\title{
Gestational Diabetes and Perinatal Outcomes: 5-Year Neonatal Intensive Care Experience
}

\author{
Atiye Fedakâr* \\ The Departments of Pediatrics, Afiyet Hospital, Turkey \\ *Corresponding author: Dr Atiye Fedakâr, The Departments of Pediatrics, Afiyet Hospital, Armağan evler mah. Akdeniz cd. Sandra evleri c Blok d-4. \\ 34762 Ümraniye, İstanbul, Turkey
}

Submission: 些- September 01, 2017; Published: 㘹 October 12, 2017

\begin{abstract}
Aim: In this study, we examined clinical and laboratory findings of mothers diagnosed with Gestational diabetes mellitus (GDM) and their babies, as well as problems emerging during the perinatal period, maternal demographics, and the interrelation between these features.
\end{abstract}

Materials and methods: In the present study, we retrospectively evaluated 180 babies who were born to mothers diagnosed with GDM, and admitted to neonatal intensive care unit (NICU) of our hospital between July 31, 2012 and July 31, 2017.

Results: Totally 3263 patients were admitted to NICU between July 31, 2012 and July 31, 2017. Among these, 180 (5.5\%) were born to mothers with GDM. Of these babies, 119 (66.1\%) were male, and 61 (33.9\%) were female. 151 (83.8\%) were term-infants, while 29 (16.2\%) were preterm infants. Mean birth weight was $3245 \pm 693(1000 \mathrm{gr}-5010 \mathrm{gr})$, the mean hospital stay length was 8,6 $\pm 1,4$ days, and the mean 5 th minute Apgar score was 8.7 \pm 1.9 . 43 (23.8\%) babies were large for gestational age (LGA), and macrosomia was detected in $16(8.8 \%)$ infants.

Mean maternal age was $31 \pm 5.4$ years, and the mean number of pregnancies was $2.3 \pm 1.1$. During their pregnancy, 12 mothers $(6.6 \%)$ had hypothyroidism, 10 (5.5\%) had urinary tract infection, $6(3.3 \%)$ had gestational hypertension, $5(2.7 \%)$ had asthma, $4(2.2 \%)$ had oligohydramniosis, $3(1.6 \%)$ had influenza infection, 3 (1.6\%) had premature rupture of membranes (PROM), $2(1.1 \%)$ had polyhydramniosis, and $1(0.5 \%)$ had hyperthyroidism. A total of $38(21.1 \%)$ mothers had $25(\mathrm{OH})$ vitamin D deficiency and 25(OH) deficiency was severe in 18 of them.

The most common metabolic disorder was hypocalcemia, which was observed in $49(27,2 \%)$ patients. A total of $42(23,3 \%)$ infants had 25 (OH) vitamin D deficiency, and $25(\mathrm{OH})$ vitamin D deficiency was severe in 18 infants.

Conclusion: GDM is a metabolic disorder requiring close monitoring and the rate of fetal loss and morbidity is 2-4 times higher compared to normal pregnancies. In addition to the associated increase in the risk of GDM, vitamin D deficiency also poses risk for the newborn. Therefore, in addition to metabolic monitoring, we think assessment of vitamin D status prior to pregnancy is necessary, because treatment of vitamin deficiency may help to reduce morbidity.

Keywords: Gestational diabetes mellitus; Neonatal complications; Caesarean section; vitamin D deficiency

\section{Introduction}

GDM is a disturbance of glucose tolerance that manifests or is diagnosed during pregnancy for the first time. Although the actual incidence is unknown, the reported rates vary between $1 \%$ and $14 \%$ in the literature [1,2]. Although there are limited number of studies on GDM in Turkey, the prevalence has been reported between 1, 2\% and $30,8 \%[3,4]$. It is one of the most important causes of increased morbidity and perinatal mortality for both mother and baby. It is responsible for $1,1-14,3 \%$ of serious complications observed in the fetus and the newborn [5].

Babies born to mothers with GDM show significantly increased rates of neonatal hypoglycemia, hypocalcemia, hyperbilirubinemia, polycytemia, congenital malformation, growth retardation, respiratory distress syndrome, sudden death, and macrosomia. Among the mothers with GDM, the prevalence's of preeclampsia, gestational hypertension, polyhdramniosis, urinary infection are increased, along with the rate of Cesarean section delivery (30-
$50 \%$ ), and the future prevalence of type 2 diabetes (26\%) and GDM at the next pregnancy (68\%) [5]. Therefore, detection of GDM and its accurate management during pregnancy have great importance for the health of both the mother and the baby.

Although there are numerous studies in the literature on babies born to diabetic mothers, the number of studies on babies born to mothers with only GDM is somehow limited. In this study, we aimed to present the clinical findings of infants born to mothers with GDM, who were admitted to our NICU during the course of a 5 -year period, as well as their problems observed at the neonatal period, and maternal demographical features, accompanied with a discussion of related literature.

\section{Materials and Methods}

The study included babies born to mothers diagnosed with GDM, who were admitted to NICU of our hospital between July 31, 
2012 and July 31, 2017. Indication for admission, birth weight, delivery type, hospital stay length, gender, maternal age, number of previous births, smoking state, blood glucose, bilirubin levels, $\mathrm{Ca}, \mathrm{CBC}, \mathrm{CRP}$ values, $5^{\text {th }}$ minute apgar score, ultrasonography (USG) and echocardiography findings were recorded. The study was approved by Ethics committee Afiyet Hospital and all recorded findings were controlled research study group.

The diagnosis of GDM was made based on the results of oral glucose tolerance test, according to the recommendations of National Diabetes Data Group (NDDG) [6]. Premature rupture of membranes (PROM) was defined as rupture of chorioamniotic membranes and release of amniotic fluid prior to initiation of labor, regardless of the gestational age.

Regardless of their birth weight, babies who were born before 37 th gestational age was defined as premature infants. Classification for LGA was made using the Lubchenko growth curve [7]. Those who were over the 90th percentile according to the gestational week were classified as LGA babies. Birth weight above $4000 \mathrm{~g}$ was defined as macrosomia [8].

Transient tachypnea of the newborn (TTN) was defined as respiratory distress occurring in term or near-term babies, emerging within 4-6 hours of delivery, which generally resolved within 3 days. Respiratory Distress Syndrome (RDS) was defined as tachypnea, chest wall retractions and cyanosis with room air, showing persistence or progression for the initial 48-96 hours, together with characteristic reticulogranular appearance and air bronchograms in the chest X-ray. Hypoglycemia was defined as blood glucose level below $47 \mathrm{mg} / \mathrm{dL}$ [9]. Patients' bilirubin levels were evaluated according to Bhutani nomogram, and hyperbilirubinemia was defined as an indirect bilirubin level that required treatment according to recommendations of American Academy of Pediatrics [10,11].

Hypocalcemia was defined as total calcium level below $7 \mathrm{mg} /$ $\mathrm{dL}$ in the blood sample. Those mothers and infants who were detected to have hypocalcemia were tested for $25(\mathrm{OH})$ vitamin D levels. 25(OH)D level below $20 \mathrm{ng} / \mathrm{mL}$ was accepted as vitamin D deficiency, while levels below $5 \mathrm{ng} / \mathrm{mL}$ was accepted as severe vitamin D deficiency. CRP level above $0.5 \mathrm{mg} / \mathrm{dL}$ was accepted as pathological. Frequency and descriptive statistics were expressed as mean \pm standard deviation and percentage.

\section{Results}

Totally 3263 patients were admitted to NICU between July, 31st 2012 and July, 31st 2017. Among these, 180 (5.5\%) were born to mothers with GDM. Of these babies, 119 (66.1\%) were male, and $61(33.9 \%)$ were female. 151 (83.8\%) were term-infants, while $29(16.2 \%)$ were preterm infants. Mean hospital stay length was 8.6 \pm 1.4 days, and mean Apgar score at $5^{\text {th }}$ minute was $8.7 \pm 1.9$. The type of delivery was Cesarean section in 145 (80.5\%) patients, and vaginal delivery in 35 (19.5\%) patients. 43 babies $(23.8 \%)$ were classified as LGA, and macrosomia was detected in 16 (8.8\%) babies.
Mean maternal age was $31 \pm 5.4$ years, and the mean number of pregnancies was 2.3 \pm 1.1 . Demographic characteristics of gestational diabetic mothers and infants were showed in Table 1 \& 2. Insulin treatment was initiated in 5 mothers in order to control their diabetes, while dietary recommendations were given to the others (Table $1 \& 2$ ).

Table 1: Demographic characteristics of gestational diabetic mothers and infants.

\begin{tabular}{|c|c|}
\hline \multirow{2}{*}{ Gender N (\%) } & Female 61 (33.9\%) \\
\cline { 2 - 2 } & Male 119 (66.1) \\
\hline \multirow{2}{*}{ Gestational age } & Term 151 (83.8\%) \\
\cline { 2 - 2 } & $\begin{array}{c}\text { Preterm 29 (16.1\%) (29 weeks to } \\
37 \text { weeks) }\end{array}$ \\
\hline Birth weight & $3245 \pm 693(1000$ gr-5010gr) \\
\hline Mean duration of hospitalization & $8.6 \pm 1.4$ day(2-83) \\
\hline Apgar score 5.minute & $8.7 \pm 1.9$ \\
\hline Ventilator follow-up time & $8.4 \pm 11.3(1-53)$ days \\
\hline
\end{tabular}

Table 2: Demographic characteristics of gestational diabetic mothers.

\begin{tabular}{|c|c|}
\hline Characteristics & N \\
\hline Maternal Age & $31 \pm 5.4$ year \\
\hline Number of maternal pregnancies & $2.3 \pm 1.1$ \\
\hline $\begin{array}{c}\text { Cesarean section/spontaneous } \\
\text { vaginal birth }\end{array}$ & $145(\% 80.5) / 35(\% 19.5)$ \\
\hline Lack of vitamin D & $38(\% 21.1)$ \\
\hline Hypothyroidism/hyperthyroidism & $12(\% 6.6) / 1(\% 0.5)$ \\
\hline Urinary tract infection & $10(\% 5.5)$ \\
\hline Smoking & $9(\% 5)$ \\
\hline Hypertensive disorders & $6(\% 3.3)$ \\
\hline Asthma & $5(\% 2.7)$ \\
\hline Diabetes treatment in pregnancy & $175(\% 97.2) / 5(\% 2.78)$ \\
\hline Diet/insulin & $4(\% 2.2)$ \\
\hline Oligohydramnios & $3(\% 1.6)$ \\
\hline Gripal infection & $3(\% 1.6)$ \\
\hline Early membrane rupture & $2(\% 1.1)$ \\
\hline Polyhydramnios & \\
\hline
\end{tabular}

The most frequent indication for admission of the newborns to NICU was TTN in 114 (63.3\%) patients, followed by TTN+sepsis in $27(15 \%)$ patients, and sepsis in $19(10.5 \%)$ patients. Other indications for admission were RDS in $5(2.7 \%)$ patients, feeding problem in $3(1.6 \%)$ patients, hyperbilirubineia in $3(1.6 \%)$ patients, asphyxia in $2(1.1 \%)$ patients, meconium aspiration in $1(0.5 \%)$ patient, congenital malformation in $1(0.5 \%)$ patient, convulsion in $1(0.5 \%)$ patient, and bilateral choanal atresia in 1 $(0.5 \%)$ patient. In terms of complications associated with birth trauma, 1 case had Erb's palsy, and 1 patient had Klumpke's paralysis. Three patients had pes equinovarus, and 1 patient had spina bifida. Forty six patients required mechanical ventilation. Mean mechanical ventilation time was $8.4 \pm 11.3$ (1-53) days. The case who had bilateral choanal atresia was operated, and did not 
develop any complications. The case who had spina bifida was referred to neurosurery. The patient who was admitted due to TTN was detected to have Down syndrome after chromosomal analysis. The case with multiple congenital anomalies had atrial septal defect (ASD) detected in echocardiography, and died on the $24^{\text {th }}$ day (Table 3).

Table 3: Gestational diabetic mother's diagnosis.

\begin{tabular}{|c|c|}
\hline Diagnosis & $\mathbf{N}=$ \\
\hline TTN & $114(\% 63.3)$ \\
\hline TTN+Sepsis & $27(\% 15)$ \\
\hline Sepsis & $19(\% 10.5)$ \\
\hline RDS & $5(\% 2.7)$ \\
\hline Hyperbilirubinemia & $3(\% 1.6)$ \\
\hline Nutritıon problem & $3(\% 1.6$ \\
\hline Asphyxia & $2(\% 1.1)$ \\
\hline Birth injury & $2(\% 1.1)$ \\
\hline Seizure & $1(\% 0.5)$ \\
\hline Meconium Aspiration & $1(\% 0.5)$ \\
\hline Congenital malformation & $1(\% 0.5)$ \\
\hline Bilateral Choanal atresia & $1(\% 0.5)$ \\
\hline Bronchopneumonia & $1(\% 0.5)$ \\
\hline
\end{tabular}

TTN: Transient Tachypnea of the Newborn RDS: Respiratory Distress Syndrome

The most common metabolic disorder was hypocalcemia, which was observed in 49 (27.2\%) patients. A total of 42 (23.3\%) patients had $25(\mathrm{OH})$ vitamin D deficiencies, and $25(\mathrm{OH})$ vitamin D deficiency was severe in 18 of them. Other metabolic disorders were hypoglycemia detected in 21 patients, hyponatremia in 9 patients, hyperbilirubinemia in 8 patients, hyperkalemia in 7 patients, hyperglycemia in 3 patients, thrombocytopenia in 2 patients, and polycytemia in 1 patient.

Table 4: Echocardiograph results of gestational diabetic mothers.

\begin{tabular}{|c|c|}
\hline Diagnosis & $\mathbf{N}=$ \\
\hline PFO & 23 \\
\hline ASD & 11 \\
\hline Normal & 8 \\
\hline Thin PDA & 3 \\
\hline ASD \pm VSD & 2 \\
\hline PPH & 2 \\
\hline ASD \pm PFO & 1 \\
\hline PDA & 1 \\
\hline Total & 51 \\
\hline
\end{tabular}

PFO: Patent Foramen Ovale; ASD: Atrial Septal Defect; VSD: Ventricular Septal Defect

PPH: Persistent Pulmonary Hypertension; PDA: Patent Ductus Arteriosus

Totally 51 patients were examined with echocardiography. Eight of these patients had normal echocardioagraphic findings. The most common cardiac defect observed in echocardiography was PFO in $23(12.7 \%)$ patients, followed by ASD in $11(6.1 \%)$ patients, thin PDA (patent ductus arteriosus) in 3 (1.6\%) patients, ASD $\pm V S D$ (ventricular septal defect) in $2(1.1 \%)$ patients, persistent pulmonary hypertension (PPH) in $2(1.1 \%)$ patients, and PDA in 1 $(0.5 \%)$ patient. The patient with PPH showed improvement with sildenafil treatment. One of the twins with RDS+PDA, who was born premature at 30th gestational week was administered ibuprofen treatment, and PDA was closed, but the case was referred to an external center due to development of intracranial hemorrhage on the $3^{\text {rd }}$ day. The case died in the external center on $10^{\text {th }}$ day (Table 4 ).

USG examination of the cases showed renal pelviectasis in 13 patients (bilateral in 4, left in 7, and right in 2 patients), hydronephrosis in 10 patients (left in 9 patients, and right in 1 patient), multiple renal cysts in 1 patient, sponge kidney in 1 patient, left hepatic cystic lesion in 1 patient, gallbladder stone in 1 patient, and ectopic kidney in 1 patient.

\section{Discussion}

According to the 1979 definition by NDDG, GDM is a disturbance of glucose tolerance that manifests or is diagnosed during pregnancy for the first time [6]. Human placental lactogen (HPL) hormone, which is released from the placenta in response to insulin densitization caused by the physiological increase in blood glucose level particularly in the second and third trimester of pregnancy, plays role in development of GDM. In addition, increased estrogen, progesterone, growth hormone, and cortisone also contribute in the insulin resistance $[12,13]$. Insulin sensitivity is decreased by $50 \%$, while insulin release is increased by $50 \%$ [14].

Among the complications of GDM, macrosomia is the most renowned. The high amounts of maternal glucose passing through the placenta stimulates fetal insulin secretion, leading to increased growth factors and macrosomia. Macrosomia is particularly responsible for increased frequency of Caesarean section or difficult labor, and for predisposing to clavicular fracture, Erb's palys and asphyxia. Because of all these complications, Caesarean section is preferred in women with GDM even though blood glucose level was well-regulated. The prevalence of macrosomia is 7-9\% in the non-diabetic population, whereas this rate has been reported up to $16-45 \%$ in case of GDM [15-18]. A study from Switzerland including 3322 mothers with GDM reported macrosomia as the most important cause of morbidity associated with birth trauma and asphyxia, and found 1.6 folds increase in the rate of emergency Cesarean sections and 2 folds increase in preeclampsia rate. The same study reported that macrosomia, asphyxia and TTN rates were 2 to 3 times higher than the rate of Erb's paralysis [19]. Ghosh studied 58 mothers with GDM, and found the rate of Cesarean section as $60.3 \%$ [20].

In our study, 145 patients (80.5\%) were born with Cesarean section, and the rate was higher than the rates reported in literature. The numbers were high due to macrosomia+ elective Cesarean sections, since the study was conducted in a private hospital. Since the elective Cesarean section deliveries were not recorded properly, we could not obtain the exact number of elective Caesarean sections, but we specified the total number of Cesarean sections instead. 
We detected macrosomia in 16 (8.8\%) babies, and this rate was consistent with the literature. In terms of complications associated with birth trauma, $1(0.5 \%)$ case had Erb's palsy, $1(0.5 \%)$ patient had Klumpke's paralysis, and $2(1.1 \%)$ patients had asphyxia.

Babies born to mothers with GDM have increased risk of hyperbilirubinemia, neonatal hypoglycemia, hyperglycemia, intrauterine sudden fetal death, intrauterine growth retardation (IUGR), preterm delivery, RDS, polycytemia, hypomagnesemia, learning disabilities, obesity at childhood, and future type II diabetes development [21]. In their study from a tertiary hospital including 136 patients with an average gestational age of 37 weeks (29\% GDM, 40\% type 2 diabetes), Watson et al. found hypocalcemia in $51 \%$ of patients, and respiratory distress in $40 \%$ of patients [22] In their study including 91 cases, of which 78 were born to mothers with GDM and 13 were born to diabetic mothers, Turkmen et al. found hyperbilirubinemia in 35 patients (25 GDM), hypoglycemia in 35 patients (29 GDM), hypocalcemia in 13 patients (12 GDM), and respiratory distress in 11 patients (8 GDM) [23]. In our study, respiratory distress was the most frequent clinical finding, observed in 146 patients $(81.1 \%)(114+$ TTN, 27 TTN + sepsis, 5 RDS). The most frequent metabolic disturbances were hypocalcemia detected in $49(27.2 \%)$ patients, and hypoglycemia detected in 21 (11.6\%) patients, which were consistent with the literature knowledge. Only hyperbilirubinemia was detected in a lower rate (4.4\%) compared to the literature, whereas other clinical findings were observed in rates similar to the literature.

Many recent studies have shown a relationship between vitamin D deficiency and insulin resistance and GDM. 25(OH) D levels below $12.5 \mathrm{ng} / \mathrm{ml}$ have been found to be associated with increased risk of GDM [24]. A total of 42 (23.3\%) patients had $25(\mathrm{OH})$ vitamin D deficiencies, and $25(\mathrm{OH})$ vitamin D deficiencies was severe in 18 of them. A total of $38(21.1 \%)$ mothers had $25(\mathrm{OH})$ vitamin D deficiencies, and $25(\mathrm{OH})$ deficiencies were severe in 18 of them.

Among babies born to diabetic mothers, cardiovascular malformations were observed in a rate of $3 \%$, and obstructive and shunted cardiac defects were detected in a rate of $1.4 \%[25,26]$. In our study, 43 of a total of 51 patients were detected to have cardiac defects. The most frequently detected cardiac defect was PFO observed in $23(12.7 \%)$ patients, followed by ASD observed in 11 $(6.1 \%)$ patients. Turkmen et al. found congenital heart defects in $12.8 \%$ of babies born to mothers with GDM, most common of which was ASD [23].

Maternal complications of GDM include preeclampsia, type II diabetes, urinary tract-vaginal infections, metabolic disturbances, progression of diabetic vasculopathies, spontaneous abortion, preterm labor, polyhydramniosis, postpartum endometritis, wound site infection and increased maternal mortality risk [21]. A study including 220 Saudian mothers with GDM found hypertension in $18.2 \%$, preterm delivery in $11.4 \%$, polyhydramniosis in $3.2 \%$, and oligohydramniosis in $2,7 \%$ of women [27]. In the present study, we detected preterm delivery in $29(16.1 \%)$ patients, urinary tract infections in $10(5.5 \%)$ patients, hypertension in $6(3.3 \%)$ patients, PROM in $3(1.6 \%)$ patients, oligohydramniosis in $4(2.2 \%)$ patients, and polyhydramniosis in $2(1.1 \%)$ patients. Congenital malformations are also related with maternal age, number of deliveries, history of GDM, and glycemic parameters as well. The prevalence of minor and major congenital malformations among babies born to mothers with GDM were reported as 6\%, and 3.8\%, respectively $[28,29]$. We detected congenital malformations in $5.5 \%$ of our patients (pes equinovarus in 3 patients, bilateral choanal atresia in 1 patient, spina bifida in 1 patient, Down syndrome in 1 patient, multiple anomalies in 1 patient, multiple renal cysts in 1 patient, sponge kidney in 1 patient, and hepatic cystic lesion at left in 1 patient).

The rate of admission to NICU among babies born to mothers with GDM was 5, 5\%. Mean hospital stay length was $8.6 \pm 1.4$ days, and mean $5^{\text {th }}$ minute Apgar score was $8.7 \pm 1.9$. The study including 220 Saudian mothers with GDM found the rate of admission for longer than 24 hours as $16.4 \%$, and did not find significant difference regarding Apgar $5^{\text {th }}$ minute score. The authors attributed the high admission rates to their routine policies, which required monitoring of babies even though there were no problems detected [27]. Another study reported NICU admission rate as $28.7 \%$ [21]. The reason why we had lower admission rate in the present study was that admissions were not for the purpose of monitoring, but only in case of a medical indication.

\section{Conclusion}

In conclusion, due to its fetal and maternal complications, GDM is a metabolic disturbance which should be given as much importance as diabetes. The rate of fetal loss and morbidity is 2-4 times higher compared to normal pregnancies. In addition to the associated increase in the risk of GDM, vitamin D deficiency also poses risk for the newborn. For this reason, in addition to metabolic follow-up, we recommend assessment of vitamin D status particularly before pregnancy.

\section{References}

1. Turok DK, Ratcliffe SD, Baxley AG (2003) Management of gestational diabetes mellitus. Am Fam Physician 68(9): 1767-1773.

2. Karakurt F, Çarlıoğlu A, Kasapoğlu B, Gümüș İ (2009) Gestasyonel Diabetes Mellitus Tanı ve Tedavisi. Yeni Tıp Dergisi 26: 134-138.

3. Moraloğlu ve ark (2004) GDM tanısında 50 gr ve 75 gr OGTT'nin karşılaștırılması. Kadın Doğum Dergisi 2(3): 184.

4. Erem C, Cihanyurdu N, Deger O ve ark (2000) Screening for gestational diabetes mellitus in northeastern Turkey (Trabzon city), European Journal of Epidemiology 18: 39.

5. Uludağ S (2013) Gebelikde diyabet tanı yönetim. Diyabet Kongresi.

6. (1979) Classification and diagnosis of diabetes mellitus and other categories of glucose intolerance. National Diabetes Data Group. Diabetes 28: 1039-1057.

7. Lubchenco LO, Hnasman C, Boyd E (1966) Intrauterine growth in length and head circumference as estimated from live births at gestational ages from 26 to 42 weeks. Pediatrics 37(3): 403-408.

8. Ovalı F (2007) Diyabetik Anne Çocuğu: Dağoğlu T, Ovalı F. Neonatoloji 2. Baskı Nobel Tip, 741-746.

9. Martin JR, Fanaroff AA, Walsh MC (2011) Neonatal-Perinatal Medicine ( ${ }^{\text {th }}$ edn), Vol 1. In: Fanaroff \& Martin's (Eds.), Saunders Elsevier (Mosby), St. Louis, Missouri, USA, pp.1308-1310. 
10. Bhutani VK, Johnson L, Sivieri EM (1999) Predictive ability of a predischarge hour-specific serum bilirubin for subsequent significant hyperbilirubinemia in healthy term and near-term newborns. Pediatrics 103(1): 6-14.

11. American Academy of Pediatrics Subcommittee on Hyperbilirubinemia (2004) Management of hyperbilirubinemia in the newborn infant 35 or more weeks of gestation. Pediatrics 114(1): 297-316.

12. World Health Organization (WHO) (2006) Definition and diagnosis of diabetes mellitus and intermediate hyperglycemia: A report of WHO/ IDF consultation. World Health Organization, Geneva.

13. Ferrara A, Kahn H, Qesenberry C, Riley C, Hedderson M (2004) An increase in the incidence of gestational diabetes mellitus: North California. Obstet Gynecol 103(3): 526-533.

14. Di Cianni G, Miccoli R, Volpe L, Lencioni C, Del Prato S (2003) İntermediate metabolism in normal pregnancy and in gestational diabetes. Diabetes Metab Res Rev 19(4): 259-270.

15. Öztürk FY, Altuntaş Y (2015) Gestasyonel diyabetes mellitus Şişli etfal hastanesi tıp bülteni. Cilt: 49 sayı.

16. Mitanchez D (2010) Fetal and neonatal complications in gestational diabetes: perinatal mortality, congenital malformations, macrosomia, shoulder dystocia, birth injuries, neonatal complications. Diabetes Metab 36: 617-627.

17. Johns K, Olynik C, Mase R, Kreisman S, Tildesley H (2006) Gestationa diabetes mellitus outcome in 394 patients. J Obstet Gynaecol Can 28(2): 122-127.

18. Naylor CD, Sermer M, Chen E, Sykora K (1996) Cesarean delivery in relation to birth weight and gestational glucose tolerance. Pathophysiology or practice style? JAMA 275: 1165-1170.

19. Persson B, Hanson U (1998) Neonatal morbidities in gestational diabetes mellitus. See comment in PubMed Commons below Diabetes Care 21(Suppl 2): B79-84.
20. Ghosh S, Ghosh K (2013) Maternal and neonatal outcomes in gestational diabetes mellitus. J Indian Med Assoc 111(5): 330-1, 336.

21. Hjertberg R, Eva N, Nordlander E, Marja-Liisa S, Wager J, et al. (2003) Maternal and fetal outcomes if gestational impaired glucose tolerance is not treated. Diabetes Care 26: 2107-2011.

22. Watson D, Rowan J, Neale L, Battin MR (2003) Admissions to neonatal intensive care unit following pregnancies complicated by gestational or type 2 diabetes. Aust N Z J Obstet Gynaecol 43(6): 429-432.

23. Türkmen M, Aydoğdu SA, Uygur Ö, Odabaşı AR, Yüksel H, et al. (2008) Diyabetik Anne Bebeklerinin Yenidoğan Dönemi Sorunları. Turkiye Klinikleri J Pediatr 17(1): 8-14.

24. Taylor SN, Wagner CL, Hollis BW (2009) Vitamin D deficiency in pregnancy and lactation and health consequences. Clin Rev Bone Miner Metab 7: 42-51.

25. Stoll BJ, Kliegman RM (2011) Infants of diabetic mother. In: Behrman RE, et al. (Eds.), Nelson Textbook of Pediatrics (19 ${ }^{\text {th }}$ edn). Saunders, Philadelphia, USA pp. 613-614.

26. Hay WW (2012) Care of the infant of the diabetic mother. Curr Diab Rep 12(1): 4-15.

27. Gasim T (2012) Gestational Diabetes Mellitus: Maternal and Perinatal Outcomes in 220 Saudi Women. Oman Med J 27(2): 140-144.

28. Catalano PM, McIntyre HD, Cruickshank JK, McCance DR, Dyer AR, et al. (2012) The hyperglycemia and adverse pregnancy outcome study: associations of GDM and obesity with pregnancy outcomes. Diabetes Care 35(4): 780-786.

29. García-Patterson A, Erdozain L, Ginovart G, Adelantado JM, Cubero JM, et al. (2004) In human gestational diabetes mellitus congenital malformations are related to pre-pregnancy body mass index and to severity of diabetes. Diabetologia 47(3): 509-514. 